Supplement of Biogeosciences, 15, 3841-3855, 2018

https://doi.org/10.5194/bg-15-3841-2018-supplement

(C) Author(s) 2018. This work is distributed under

the Creative Commons Attribution 4.0 License.

(c) (1)

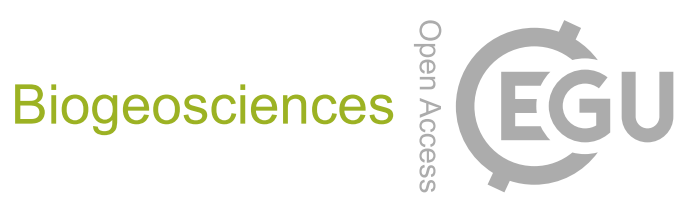

Supplement of

\title{
Utilizing the Drake Passage Time-series to understand variability and change in subpolar Southern Ocean $p \mathrm{CO}_{2}$
}

Amanda R. Fay et al.

Correspondence to: Amanda R. Fay (afay@1deo.columbia.edu)

The copyright of individual parts of the supplement might differ from the CC BY 4.0 License. 


\section{Supplementary Figure 1}

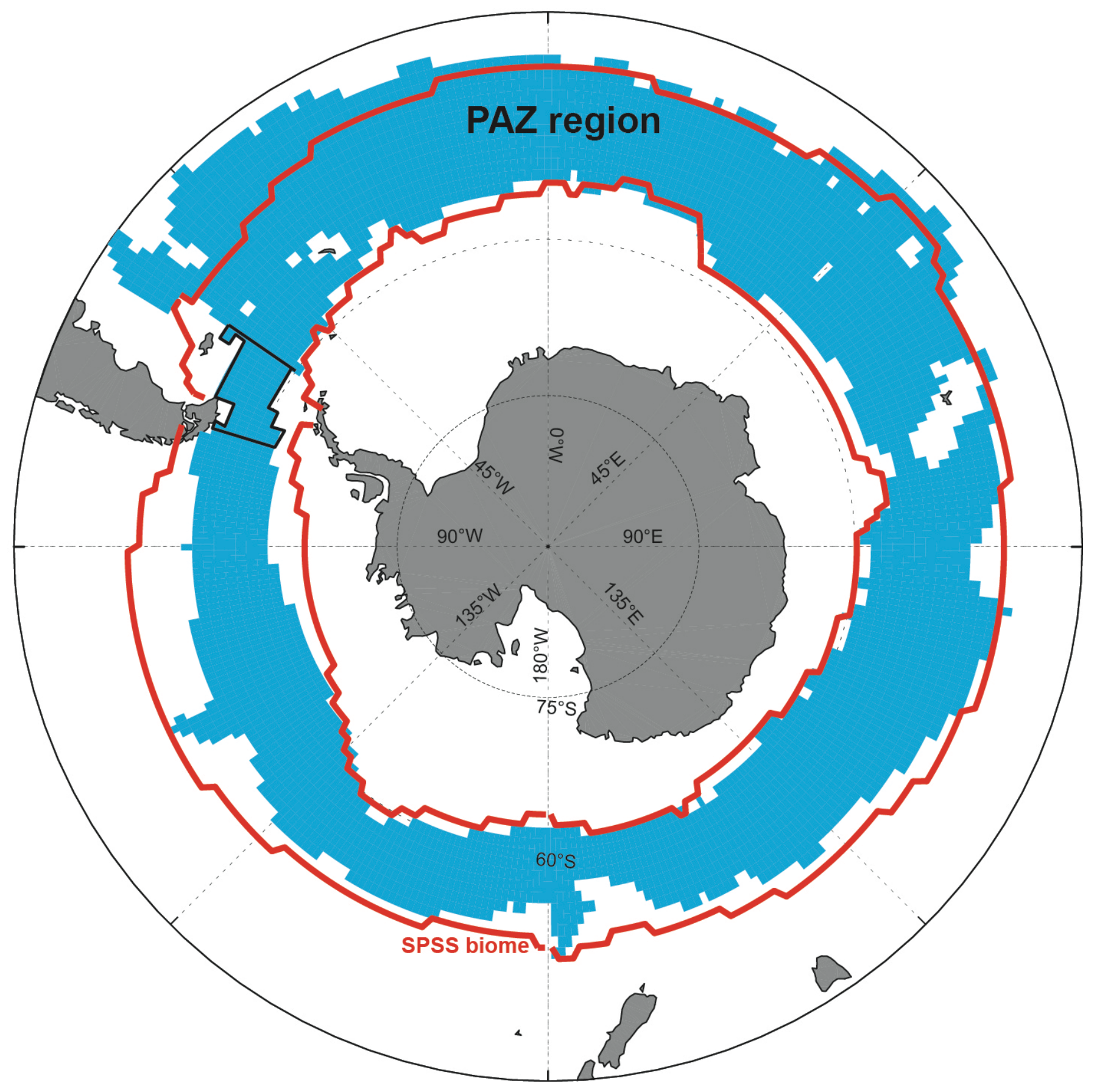




\section{Supplementary Figure 2}

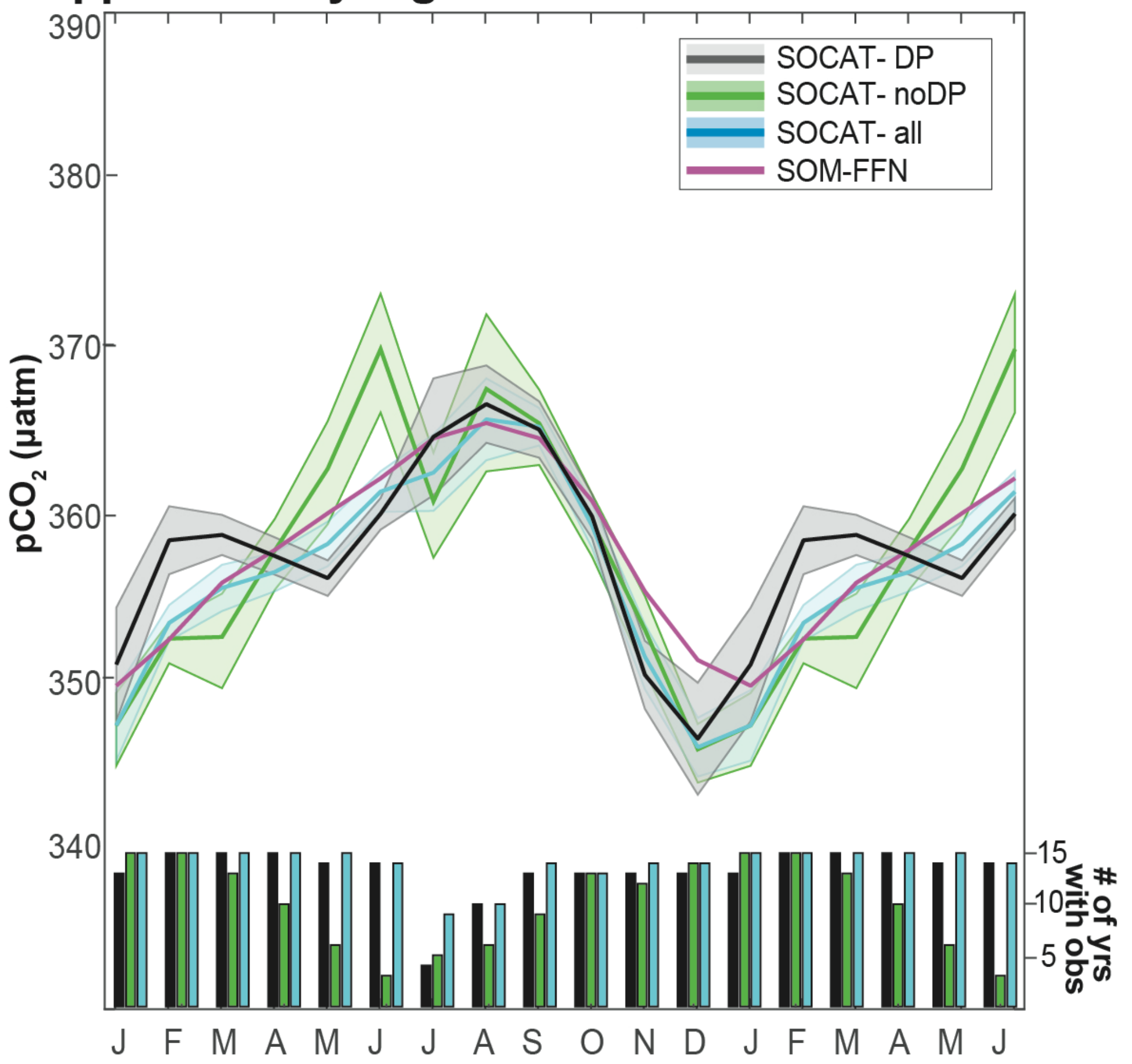




\section{Supplementary Figure 3}

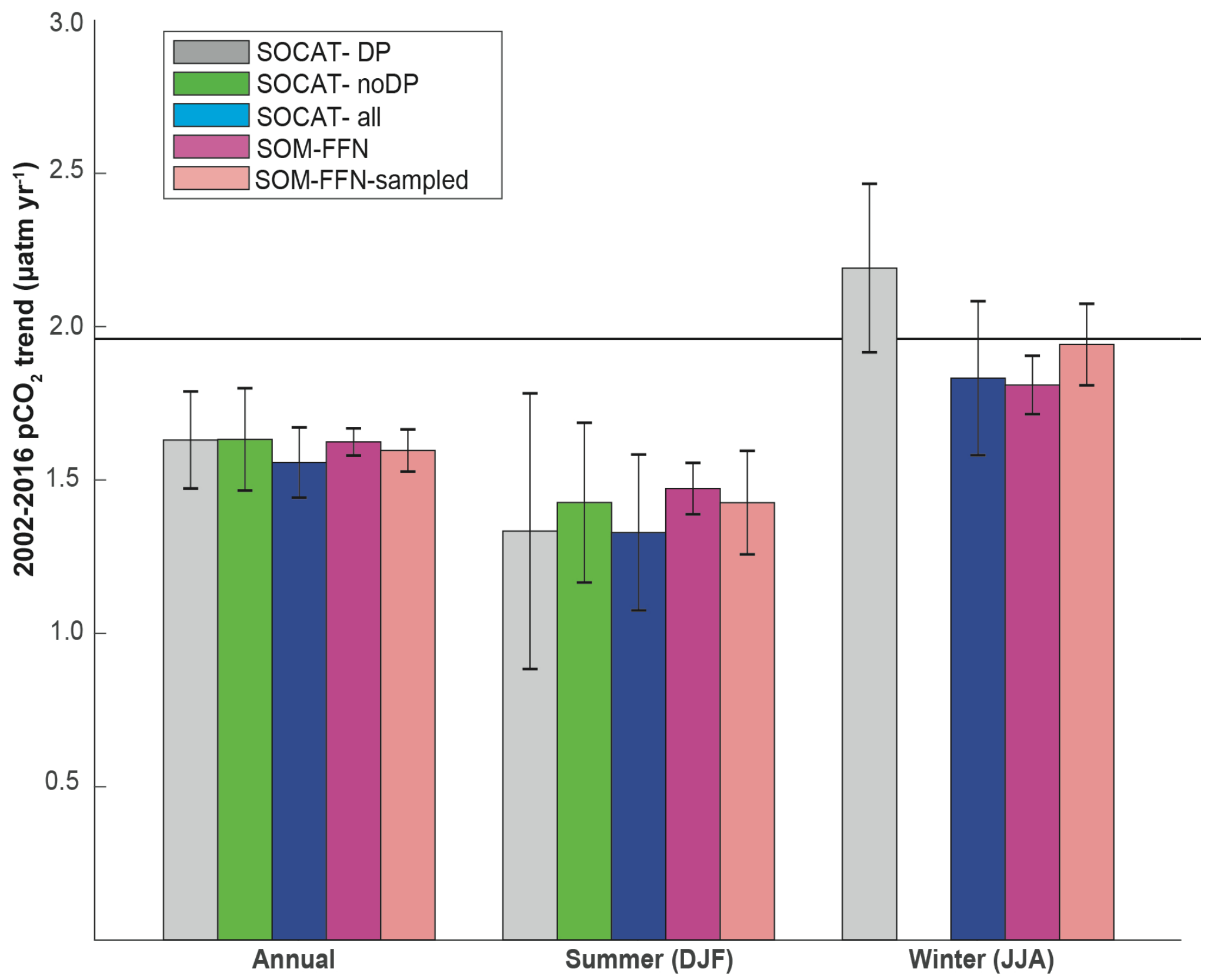


SPSS Trends

\begin{tabular}{|l|c|c|c|}
\hline & Annual & DJF (summer) & JJA (winter) \\
\hline SOCAT-DP & $1.38 \pm 0.16$ & $1.04 \pm 0.41$ & $1.96 \pm 0.31$ \\
\hline SOCAT-noDP & $1.59 \pm 0.16$ & $1.44 \pm 0.25$ & \\
\hline SOCAT-all & $1.44 \pm 0.12$ & $1.23 \pm 0.22$ & $1.80 \pm 0.26$ \\
\hline SOM-FFN & $1.65 \pm 0.04$ & $1.46 \pm 0.08$ & $1.87 \pm 0.09$ \\
\hline SOM-FFN sampled & $1.41 \pm 0.09$ & $1.33 \pm 0.18$ & $1.86 \pm 0.26$ \\
\hline
\end{tabular}

PAZ Trends

\begin{tabular}{|l|c|c|c|}
\hline & Annual & DJF (summer) & JJA (winter) \\
\hline SOCAT-DP & $1.63 \pm 0.16$ & $1.33 \pm 0.45$ & $2.19 \pm 0.28$ \\
\hline SOCAT-noDP & $1.63 \pm 0.17$ & $1.43 \pm 0.26$ & \\
\hline SOCAT-all & $1.56 \pm 1.11$ & $1.33 \pm 0.25$ & $1.83 \pm 0.25$ \\
\hline SOM-FFN & $1.62 \pm 0.04$ & $1.47 \pm 0.08$ & $1.81 \pm 0.10$ \\
\hline SOM-FFN sampled & $1.60 \pm 0.07$ & $1.43 \pm 0.17$ & $1.94 \pm 0.13$ \\
\hline
\end{tabular}

